\title{
Estimation of body composition from bioelectrical impedance of body segments: comparison with dual-energy X-ray absorptiometry
}

\author{
BY S. P.STEWART ${ }^{1}$, P. N. BRAMLEY ${ }^{2}$, R. HEIGHTON ${ }^{2}$, J. H. GREEN ${ }^{2}$, \\ A. HORSMAN ${ }^{1 *}$, M. S. LOSOWSK Y ${ }^{2}$ AND M. A. SMITH ${ }^{1}$ \\ Centre for Bone and Body Composition Research, Department of Clinical Medicine, University of \\ Leeds at ${ }^{1}$ The General Infirmary, Leeds LSI 3EX, ${ }^{2}$ St James's University Hospital, Leeds LS9 $7 T F$
}

(Received 3 October 1991-Accepted 4 June 1992)

\begin{abstract}
In twenty-eight healthy subjects, ten men and eighteen women, with a range in body mass index (BMI) of $17.9-31.6 \mathrm{~kg} / \mathrm{m}^{2}$ and an age range $20-60$ years, body composition was estimated by dual-energy $\mathrm{X}$ ray absorptiometry (DEXA), skinfold anthropometry (SFA) and bioelectrical impedance analysis (BIA) of the 'whole body' and body segments. In thirteen subjects muscle mass was also estimated by $24 \mathrm{~h}$ urinary creatinine excretion. The relationship between fat-free mass (FFM) determined by DEXA and the impedance index of each body segment (calculated as length ${ }^{2} /$ impedance $(Z)$ ) was analysed. The strongest correlation was between FFM (DEXA) and height ${ }^{2} /$ 'whole-body' $Z\left(Z_{\mathrm{w}}\right)$ ( $r$ 0.97 for the combined sexes, standard error of estimate (SEE) $2.72 \mathrm{~kg}$ ). Separate prediction equations were found to be necessary for males and females when estimating FFM from BIA measurement of the arm (for men, $r 0.93$, SEE $1.98 \mathrm{~kg}$; for women, $r 075$, SEE $2.87 \mathrm{~kg}$ ). Muscle mass derived from $24 \mathrm{~h}$ creatinine excretion showed weak correlation with FFM (DEXA) $(r 0.57, P=0.03)$ and no correlation with FFM (SFA). FFM (SFA) correlated well with both FFM (DEXA) $(r 0.96$, SEE $=3.12 \mathrm{~kg})$ and with height ${ }^{2} / Z_{\mathrm{w}}(r 0.92$, SEE $4.52 \mathrm{~kg}$ ). Measurement of the impedance of the arm offers a simple method of assessing the composition of the whole body in normal individuals, and it appears comparable with other methods of assessment.
\end{abstract}

Body composition: Bioelectrical impedance: DEXA

Measurement of body composition is valuable for monitoring many endocrine, metabolic and nutritional disorders, together with the response to treatment. In general it involves the use of expensive and specialist techniques such as hydrostatic densitometry, neutron activation analysis, measurement of total body $\mathrm{K}$ and now dual-energy $\mathrm{X}$-ray absorptiometry (DEXA).

Dual photon absorptiometry (DPA) was originally developed to measure bone mineral content, but the technique can be used to determine lean body mass and fat mass (Mazess et al. 1984, 1990; Gotfredsen et al. 1986). The use of two photon energies (produced either by an isotope source (DPA) or by an X-ray source (DEXA)) allows discrimination of two substances in a given system, which are assumed to be bone mineral and soft tissue of uniform composition. After calculation of total body bone mineral, the remaining soft tissue mass is separated into fat and fat-free components. Fat mass derived from DPA measurements has been shown to correlate well with fat mass calculated from hydrodensitometry and total body $\mathrm{K}$ measurements, and with the results of neutron activation (Hassager et al. 1989; Heymsfield et al. 1989).

\footnotetext{
* Present address: Department of Applied Biology, University of Hull, Hull HU6 7RX.
} 
Bioelectrical impedance analysis (BIA) is a method of measuring body composition which is safe, non-invasive and rapid, allowing repeated estimations at the bedside. The accuracy of the technique has been measured in normal subjects by comparison with hydrodensitometry, isotope dilution, total body $\mathrm{K}$ and standard skinfold anthropometry (Presta et al. 1983; Lukaski et al. 1986).

The validity of BIA depends heavily on assumptions of a constant relationship between water, electrolytes, lean body mass and fat in the body, but the effects of abnormal hydration and electrolyte disturbances, such as are found in patients with chronic liver diseases, are not well documented. These patients suffer a rapid loss of muscle bulk with excessive fluid accumulation in the abdomen, which can lead to problems in the interpretation of BIA measurements of the whole body. Baumgartner et al. (1989) have shown that measurements of the resistance and length of the arm can be used in place of the whole body in estimating body composition from BIA in comparison with underwater weighing.

The purpose of the present study was to determine the relationship in healthy people between BIA measurement of body segments and estimation of body composition by DEXA with a view to assessing body composition changes in patients with abnormal abdominal fluid retention resulting from chronic liver disease. A comparison with muscle mass estimated by $24 \mathrm{~h}$ urinary creatinine excretion and with fat-free mass (FFM) derived from anthropometry was also made.

\section{SUBJECTS AND METHODS}

\section{Subjects}

Twenty-eight healthy Caucasian volunteers (age range 20-60 years, BMI range $17.9-31.6 \mathrm{~kg} / \mathrm{m}^{2}$ ) were recruited for the study from University and hospital staff. The group consisted of ten men and eighteen women who were unselected in terms of body composition. All subjects gave their informed consent to the study, which was approved by the Leeds Eastern Health Authority Ethics Committee. Thirteen members of the group (five men, eight women) agreed to collect a timed $24 \mathrm{~h}$ urine specimen for urinary creatinine excretion determination.

\section{Bioelectrical impedance}

Bioelectrical impedance was measured using a Holtain body composition analyser (Holtain Ltd, Crosswell, Dyfed) which applies a constant current of $800 \mu \mathrm{A}$ at $50 \mathrm{kHz}$ across the body. Measurement of impedance was made by placing two impedance plethysmograph electrodes on the back of the left wrist joint and two electrodes on the front of the left ankle joint. At both the wrist and ankle the excitation current was introduced at the distal (source) electrode and the voltage drop detected by the proximal (receiving) electrode. After positioning the electrodes on the subject and connecting to the analyser, the impedance value was read as soon as it was stable, usually after approximately 5-10 s. Before each reading was taken the system was calibrated against an internal precision $400 \Omega$ resistor.

Four sites similar to those used by Baumgartner et al. (1989) were chosen for positioning the electrodes. These were as follows; site A (hand), site B (shoulder), site C (thigh) and site $\mathrm{D}$ (foot) (Fig. 1). At site $\mathrm{A}$ the receiving electrode was placed anteriorly in the midpoint between ulnar and radial processes and the source electrode $30 \mathrm{~mm}$ distal to this on the back of the hand. The receiving electrode at the shoulder (site B) was positioned in the midpoint between the anterior axillary fold and the acromion, and the source $30 \mathrm{~mm}$ distal to this. For site $\mathrm{C}$ the receiving electrode was placed on the midpoint of the anterior thigh in the same plane as the gluteal crease and the source electrode was placed $30 \mathrm{~mm}$ proximal 


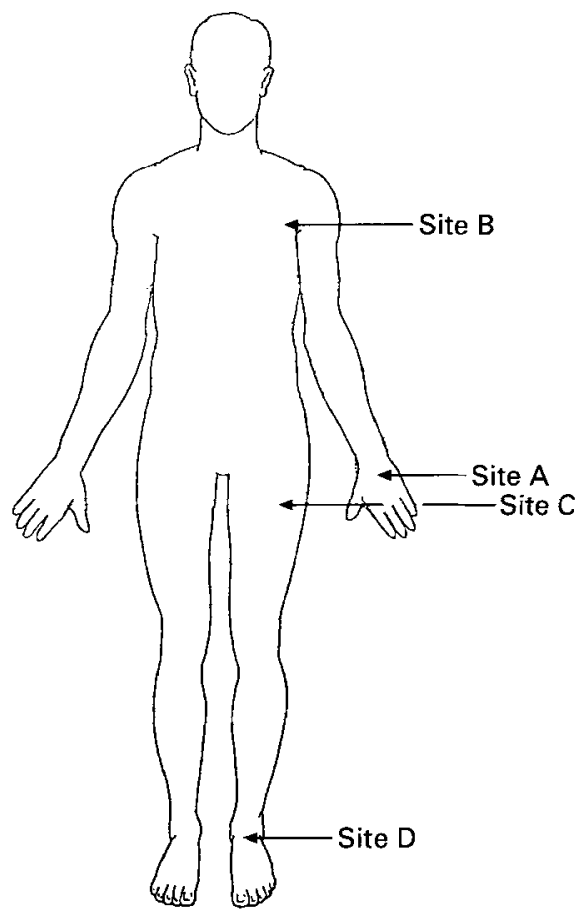

Fig. 1. Location of sites for the positioning of electrodes for measurement of body segment impedances in healthy male and female volunteers. For details of procedures, see p. 646.

to this. The source and receiving electrodes were reversed at sites $\mathrm{B}$ and $\mathrm{C}$ when measuring the trunk. The electrodes were positioned on the foot (site D) in the conventional position with the receiving electrode at the midpoint anteriorly between the malleoli of the ankle and the source electrode $30 \mathrm{~mm}$ distal to this.

During measurement the subjects lay supine with legs and arms angled outwards at approximately $30^{\circ}$ so that the medial surfaces of the limbs did not touch the rest of the body. Measurements were taken on the left-hand side of the body as follows: impedance of the arm (site A to site B); trunk (site B to site C, electrodes reversed as described previously); leg (site C to site D); whole body (site A to site D). Arm and leg lengths were measured between the centres of the receiving electrodes.

The precision of the method was determined by taking three sets of measurements on each of three subjects on one day. The coefficient of variation (CV) was calculated to be $1.0 \%$ for whole body, arm and leg impedance, and $4.0 \%$ for the trunk measurement.

\section{Body composition by DEXA}

Body composition was determined by DEXA by scanning each subject on a Lunar DPX Bone Densitometer (Lunar Corporation, Madison, Wisconsin). This equipment uses an $\mathrm{X}$-ray source which produces a dual-energy beam with energies of 38 and $70 \mathrm{keV}$ by K-edge filtering using cerium. The DPX system performs rectilinear scans over the entire length of the patient's body, beginning at the top of the head and moving downwards towards the feet. A total body scan takes approximately $15 \mathrm{~min}$ and the subject receives less than $0.5 \mu \mathrm{Sv}$ radiation exposure.

The analysis software (Lunar Version 3.2) calculates three sets of body composition values; $g$ fat tissue $\left(\mathrm{Fat}_{\mathrm{DEXA}}\right)$, $\mathrm{g}$ lean tissue and the percentage fat body mass compared with 
the total soft tissue mass. Total bone mineral content is also determined. FFM (kg) was calculated as follows:

$$
\mathrm{FFM}=\text { body weight }-\left(\mathrm{Fat}_{\mathrm{DEXA}} / 1000\right) .
$$

The precision of this method was determined by scanning a group of six people six times each at weekly intervals. The CV was calculated to be $4.2 \%$ for fat tissue mass and $2 \cdot 2 \%$ for lean tissue mass. Body weight was measured to the nearest $0.5 \mathrm{~kg}$ and height in metres to the nearest $\mathrm{cm}$.

\section{Skinfold anthropometry $(S F A)$}

Skinfold thicknesses were measured to the nearest $0.1 \mathrm{~mm}$ at four sites; biceps, triceps, subscapular and supra-iliac, using Harpenden calipers. All measurements were made on the left-hand site of the body by the same operator. The mass of body fat was calculated from the body weight and the sum of the four skinfold thicknesses according to the method of Durnin \& Womersley (1974). Precision was determined by measuring four people four times each on the same day and was calculated to be $1.4 \%$ (CV).

\section{Urinary creatinine excretion measurements}

Urinary creatinine ( $24 \mathrm{~h}$ ) is generally acknowledged to be proportional to FFM and muscle mass in normal subjects (Lukaski, 1987) and is often used as a measure of body muscle mass. However, the technique depends on accurately timed urine collections and is affected by factors such as stress, menstrual cycle and dietary intake of creatinine. In the present study we estimated muscle mass from creatinine excretion (Heymsfield et al. 1983) in order to determine the relative accuracy of creatinine excretion compared with impedance measurements, DEXA FFM analysis and total body muscle mass derived from anthropometry using equations developed by Heymsfield et al. (1982).

In thirteen volunteers, one timed urine collection over $1 \mathrm{~d}$ was performed to determine 24-h urinary creatinine excretion and, hence, muscle mass. The volunteer's normal diet was followed in the week preceding and during the collection period. After recording the total volume, a portion of urine was assayed in duplicate for creatinine using a quantitative colorimetric method (Sigma Diagnostics, UK, Procedure no. 555) with a CV of $<8.0 \%$.

\section{Calculations and statistical analysis}

Mathematical relationships between impedance variables and FFM have been determined by several investigators and height $(\mathrm{Ht})^{2} /$ resistance has been shown to be a "significant predictor of FFM' (Hoffer et al. 1969; Lukaski et al. 1985). Indices for each body segment were calculated using the formula length $(L)^{2} /$ impedance $(Z)$ for the leg $\left(L_{1}, Z_{1}\right)$ and arm $\left(L_{\mathrm{a}}, Z_{\mathrm{a}}\right)$.

Linear-regression analysis was performed using a commercial software package (Statgraphics Version 3.0) to evaluate the relationship between FFM from DEXA and SFA measurements and the indices for each body segment, together with $\mathrm{Ht}^{2} /$ whole-body $Z\left(Z_{\mathrm{w}}\right)$. Multiple-regression analyses were applied to the data with $\mathrm{Ht}^{2} / Z_{\mathrm{w}}$ (or $L^{2} / Z$ ) and sex offered as possible predictors. FFM determined by DEXA was used as the dependent variable. Before pooling the values from males and females the differences between the slopes and intercepts were tested for statistical significance. Differences were tested for significance by the pooled two-sided Student's $t$ test.

A summary of the physical characteristics of the participants together with the results of the determination of fat and FFM by DEXA and SFA is shown in Table 1. The men and 
Table 1. Physical characteristics of the study population

\begin{tabular}{|c|c|c|c|c|}
\hline & \multicolumn{2}{|c|}{$\operatorname{Men}(n 10)$} & \multicolumn{2}{|c|}{ Women (n 18) } \\
\hline & Mean & SD & Mean & SD \\
\hline Age (years) & 36.64 & 14.09 & $35 \cdot 92$ & 8.87 \\
\hline Weight $(\mathrm{kg})$ & $73 \cdot 2$ & $6 \cdot 2$ & $61 \cdot 1$ & $9 \cdot 6$ \\
\hline Height (m) & 1.750 & 0.072 & 1.638 & 0.059 \\
\hline BMI $\left(\mathrm{kg} / \mathrm{m}^{2}\right)$ & 24.04 & 3.03 & $22 \cdot 77$ & 3.45 \\
\hline Leg length (mm) & $606 \cdot 0$ & $66 \cdot 5$ & $572 \cdot 2$ & $44 \cdot 8$ \\
\hline Arm length (mm) & 527.0 & $31 \cdot 3$ & 513.9 & $36 \cdot 0$ \\
\hline Fat (DEXA) (kg) & $13 \cdot 35$ & 5.05 & $20 \cdot 27$ & 7.02 \\
\hline FFM (DEXA) (kg) & 59.85 & $5 \cdot 17$ & 40.79 & $4 \cdot 22$ \\
\hline Fat (SFA) (kg) & $12 \cdot 56$ & 4.88 & $19 \cdot 0$ & 6.04 \\
\hline FFM (SFA) (kg) & $60 \cdot 64$ & $5 \cdot 37$ & $42 \cdot 06$ & $5 \cdot 60$ \\
\hline
\end{tabular}

FFM, fat-free mass; DEXA, dual-energy X-ray absorptiometry; SFA, skinfold anthropometry; BMI, body mass index.

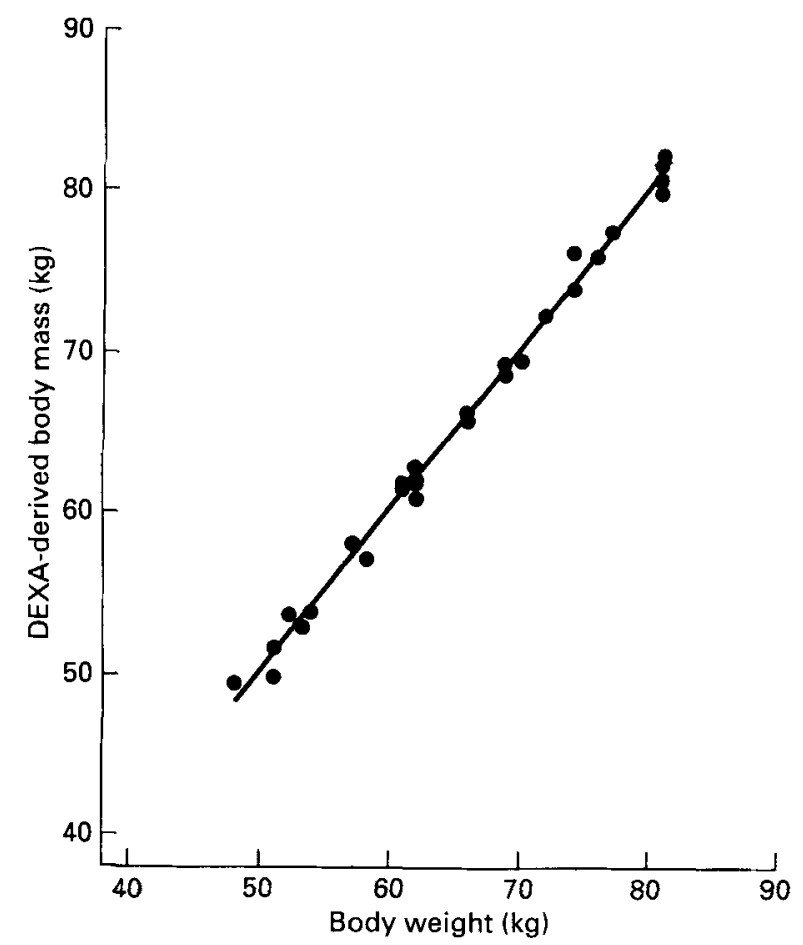

Fig. 2. Relationship between body weight and dual-energy X-ray absorptiometry (DEXA)-derived body mass (obtained by summing fat tissue + lean tissue + total bone mineral content) in healthy male and female volunteers. For details of procedures, see p. 647.

women did not differ significantly for age, but the men were heavier and taller than the women. No significant difference was found between the FFM as measured by the two techniques in either sex. The proportion of fat relative to FFM is different in the two sexes, women having a greater amount of fat tissue and correspondingly less lean tissue. We 
Table 2. Body segment impedances $(\Omega)$ of healthy male and female volunteers*

\begin{tabular}{|c|c|c|c|c|}
\hline & \multicolumn{2}{|c|}{ Men $(n 10)$} & \multicolumn{2}{|c|}{ Women $(n 18)$} \\
\hline & Mean & SD & Mean & SD \\
\hline Whole body & $446 \cdot 70$ & 44.23 & $552 \cdot 83$ & $48 \cdot 33$ \\
\hline Leg & $196 \cdot 70$ & $23 \cdot 15$ & $232 \cdot 83$ & $22 \cdot 71$ \\
\hline Trunk & $68 \cdot 10$ & 7.06 & 85.94 & 8.65 \\
\hline Arm & $206 \cdot 30$ & $20 \cdot 21$ & $287 \cdot 78$ & 27.92 \\
\hline Sum of segments & $471 \cdot 10$ & $41 \cdot 77$ & $606 \cdot 56$ & $48 \cdot 37$ \\
\hline$\frac{\text { Sum of segments }}{\text { whole body }}(\%)$ & \multicolumn{2}{|c|}{106} & \multicolumn{2}{|c|}{110} \\
\hline
\end{tabular}

* For details of subjects and procedures, see Table 1 and p. 646.

Table 3. Regressions of fat-free mass (dual-energy $X$-ray absorptiometry; $D E X A$ ) on bioelectric impedance variables in healthy male and female volunteers

\begin{tabular}{|c|c|c|c|c|}
\hline & Intercept & Slope $(95 \%$ CI $)$ & $r$ & SEE \\
\hline \multicolumn{5}{|l|}{$\mathrm{Ht}^{2} / Z_{\mathrm{w}}$} \\
\hline Men & $-4 \cdot 06$ & $0.93(0.57-1.28)$ & 0.90 & $2 \cdot 43$ \\
\hline Women & $10 \cdot 13$ & $0.63(0.40-0.85)$ & 0.82 & 2.47 \\
\hline Combined & -2.95 & $0.90(0-80-1.00)$ & 0.97 & $2 \cdot 72$ \\
\hline \multicolumn{5}{|l|}{$L_{\mathrm{a}}{ }^{2} / Z_{\mathrm{a}}$} \\
\hline Men & $15 \cdot 59$ & $3 \cdot 27(2 \cdot 29-4 \cdot 24)$ & 0.93 & 1.98 \\
\hline Women & $20 \cdot 31$ & $2 \cdot 21(1 \cdot 21-3 \cdot 20)$ & 0.75 & $2 \cdot 87$ \\
\hline \multicolumn{5}{|l|}{$L_{1}^{2} / Z_{1}$} \\
\hline Men & $40 \cdot 83$ & $1 \cdot 01(-0 \cdot 16-2 \cdot 18)$ & 0.56 & $4 \cdot 56$ \\
\hline Women & $23 \cdot 62$ & $1 \cdot 21(0 \cdot 26-2 \cdot 16)$ & 0.55 & 3.63 \\
\hline
\end{tabular}

$95 \% \mathrm{CI}, 95 \%$ confidence interval; $r$, correlation coefficient ; SEE, SE of estimate; $L_{a}, Z_{a}, L_{1}, Z_{1}$, length (cm) and impedance $(\Omega)$ of arm and leg respectively.

found almost identical body weight obtained by conventional weighing and by summing fat mass, lean tissue mass and total bone mineral as measured by DEXA (Fig. 2).

Table 2 shows a summary of the impedance measurements for whole body, leg, trunk and arm segments. Nearly all the impedance of the whole body in each sex was determined by $Z_{\mathrm{a}}$ and $Z_{1}$. For both men and women the sum of $Z_{1}, Z_{\mathrm{a}}$ and $Z$ for the trunk was greater than $Z_{\mathrm{w}}$ by approximately $6 \%$ for males and $10 \%$ for females. The method of placement of the electrodes eliminated the possibility of overlapping of body segment $Z$ measurements.

Results for the regression of FFM (derived from DEXA) on $\mathrm{Ht}^{2} / Z_{\mathrm{w}}$ and on $L_{\mathrm{a}}{ }^{2} / Z_{\mathrm{a}}$ and $L_{1}{ }^{2} / Z_{1}$ are shown in Table 3 for each sex. The values for men and women were combined for the regression of FFM on $\mathrm{Ht}^{2} / Z_{\mathrm{w}}$, as multiple-regression analysis did not demonstrate any significant effect of sex (Fig. 3). However, this was not found to be the case for both the arm and the leg segments, and the values for men and women were, therefore, not combined. Fig. 4 shows the regression of FFM (DEXA) on $L_{\mathrm{a}}{ }^{2} / Z_{\mathrm{a}}$ for both sexes. The regression of FFM $v . \mathrm{Ht}^{2} / Z_{\mathrm{w}}$ for the combined sexes had the highest correlation coefficient $(r)$. Whilst the regression of FFM v. $L_{\mathrm{a}}{ }^{2} / Z_{\mathrm{a}}$ for the men produced an $r$ value higher and an SEE lower than those produced by the regression FFM $v . \mathrm{Ht}^{2} / Z_{\mathrm{w}}$, the regression for the comparable female values produced a lower $r$ value and a higher SEE. 


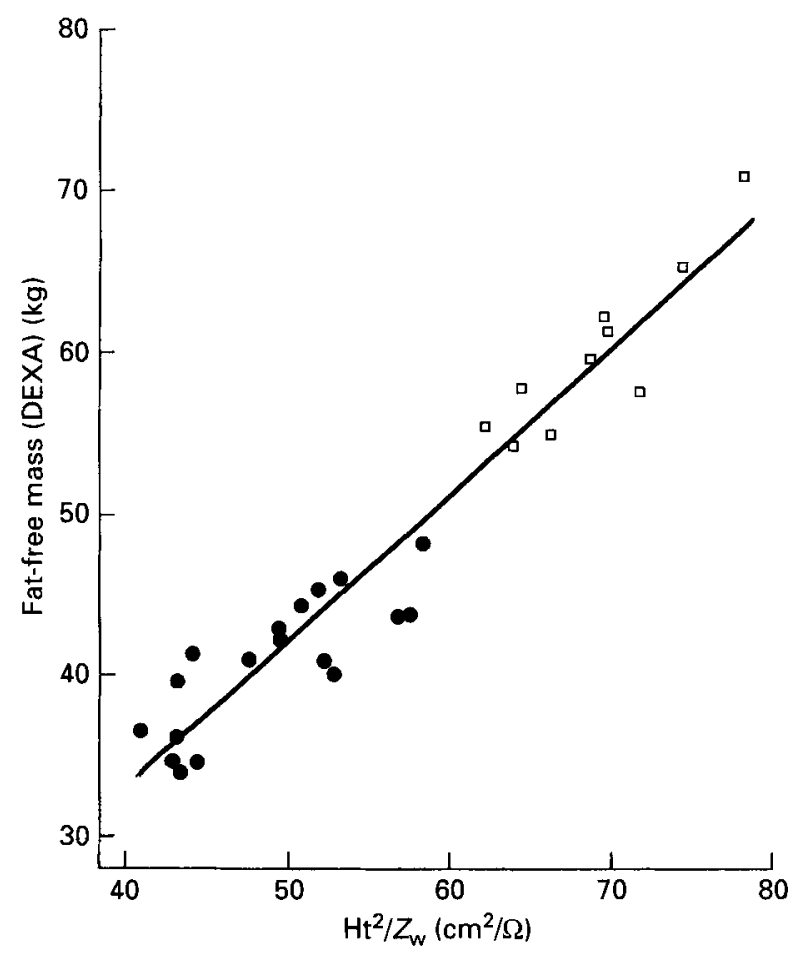

Fig. 3. Regression of fat-free mass (dual-energy X-ray absorptiometry; DEXA) $v$. height (Ht) ${ }^{2} /$ whole-body impedance $\left(Z_{w}\right)$ for the combined sexes in healthy male $(\square)$ and female $(O)$ volunteers. For details of procedures, see p. 647. Regression equation; $y=-2.95+0.90 x ; r 0.97$.

Table 4 illustrates for men and women, separately and combined, the correlation coefficients for FFM by SFA, BIA and DEXA. Both methods produced comparable values for $r$ and the SEE in relation to DEXA.

When body muscle mass derived from creatinine excretion was compared with muscle mass derived from anthropometry in thirteen subjects there was no significant correlation $(r 0.44, P=0.15)$. A significant correlation was found $(r 0.57, P=0.03)$ when comparing the creatinine-derived muscle mass $v$. FFM (DEXA). However, the relationship between anthropometrically derived muscle mass and FFM (DEXA) was highly significant ( $r 0.94, P=0.00001)$. Similarly in these thirteen subjects the correlation of impedance values as expressed by $\mathrm{Ht}^{2} / Z_{\mathrm{w}}$ and FFM measured by DEXA was highly significant $(r 0.96$, $P=0.00001)$.

\section{DISCUSSION}

The results shown in Table 2 illustrate two points, in line with the findings of other workers (Settle et al. 1988; Baumgartner et al. 1989; Fuller \& Elia, 1989). First, the sum of impedance measurements of individual segments was greater than $Z_{w}$ by $6 \%$ for men and $10 \%$ for women. Baumgartner et al. (1989) demonstrated that the sum of the body segment resistances (measured by the RJL Systems analyser) was approximately $16 \%$ greater than the resistance of the whole body for both men and women in his study. Fuller \& Elia (1989) found that the sum of segmental impedances (measured by the Holtain analyser) was consistently $10 \%$ higher than the whole-body measurement in both men and women. This is perhaps not surprising, since regarding the human body as a series of separate resistances which can be summed is a simplification of the true situation. As suggested by Fuller $\&$ Elia 


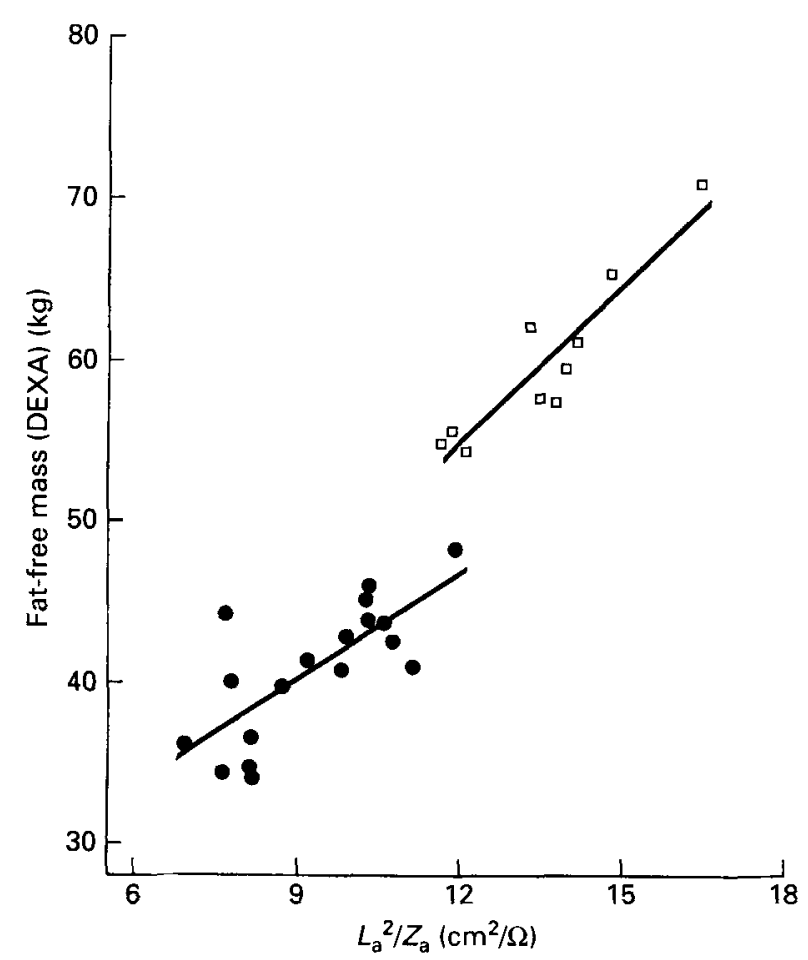

Fig. 4. Regression of fat-free mass (dual-energy X-ray absorptiometry; DEXA) $v$. arm length $\left(L_{\mathrm{a}}\right)^{2} / \mathrm{arm}$ impedance $\left(Z_{\mathrm{a}}\right)$ for each sex in healthy male $(\square)$ and female $(O)$ volunteers. For details of procedures, see p. 647. Regression equations; men $y=15.59+3.27 x ; r 0.93$, women $y=20.31+2.21 x ; r 0.75$.

Table 4. Correlation coefficients for fat-free mass (FFM) by skinfold anthropometry $(S F A)$ and bioelectrical impedance $(B I A)$ in relation to dual-energy $X$-ray absorptiometry $(D E X A)$ in healthy male and female volunteer*

\begin{tabular}{|c|c|c|c|c|c|c|}
\hline & \multicolumn{2}{|c|}{ Men $(n 10)$} & \multicolumn{2}{|c|}{ Women (n 18) } & \multicolumn{2}{|c|}{ Combined ( $n$ 28) } \\
\hline & $r$ & SEE & $r$ & SEE & $r$ & SFE \\
\hline $\begin{array}{l}\text { SFA } \\
\text { BIA }\end{array}$ & 0.95 & 1.82 & $0 \cdot 76$ & $3 \cdot 76$ & 0.96 & $3 \cdot 12$ \\
\hline Whole body & 0.90 & $2 \cdot 43$ & 0.82 & $2 \cdot 47$ & 0.97 & $2 \cdot 72$ \\
\hline Arm segment & 0.93 & 1.98 & 0.75 & $2 \cdot 87$ & - & $\ldots$ \\
\hline Leg segment & 0.56 & $4 \cdot 56$ & 0.55 & $3 \cdot 63$ & - & $\cdots$ \\
\hline
\end{tabular}

SEE, SE of estimate.

* For details of subjects and procedures, see Table 1 and pp. 646-648.

(1989), there may be a certain overlap in the conduction pathways of adjacent segments, e.g. the shortest pathway for the current during whole-body measurement is via the tissues around the axilla, but when measuring the arm or trunk the electrodes are placed on the acromion to aid reproducibility. Any errors arising from imperfect contact between skin and electrodes will be magnified by the multiple measurements of segmental impedance compared with the single measurement of $Z_{w}$, and could also contribute to the discrepancy.

Second, the impedance of the body appears to be determined mainly by the arm and the 
leg. The arm, which is only a small percentage (approximately 4 ) of body weight (Clarys \& Marfell-Jones, 1986), accounts for about half the total body impedance, whilst the trunk, which is approximately $46 \%$ of body weight, contributes only about $15 \%$ to $Z_{w}$. This can be expected, since the resistance of a conductor is inversely proportional to its crosssectional area, and therefore the larger the cross-sectional area the smaller the resistance to current flow.

The results demonstrate that indices of the conductive volume of the $\operatorname{arm}\left(L_{\mathrm{a}}^{2} / Z_{\mathrm{a}}\right)$ can be used to estimate body composition in place of $\mathrm{Ht}^{2} / Z_{\mathrm{w}}$. However, separate regression equations may be necessary for men and women for predicting FFM from $L_{\mathrm{a}}{ }^{2} / Z_{\mathrm{a}}$. The lower values of $r$ and higher values for SEE obtained when correlating FFM (DEXA) with $L^{2} / Z$ for the leg for both sexes suggest that the leg is not a suitable limb for localized BIA. The error of prediction for FFM from whole-body BIA in the combined sexes was $2.72 \mathrm{~kg}$, similar to that reported by previous investigators, Lukaski et al. $(1985,1986)$ reporting an SEE of approximately $2.5 \mathrm{~kg}$, whilst Baumgartner et al. (1989) found a somewhat larger SEE of $3.65 \mathrm{~kg}$. This is also true of BIA measurements of the arm; SEE of $1.98 \mathrm{~kg}$ for males and $2.87 \mathrm{~kg}$ for females were found in the present study compared with $4.48 \mathrm{~kg}$ (men) and $3.90 \mathrm{~kg}$ (women) (Baumgartner et al. 1989) and $2.75 \mathrm{~kg}$ (combined data, Fuller \& Elia, 1989).

The measurement of FFM by DEXA and by anthropometry correlates well in healthy subjects. However, it must be borne in mind that the reliability of skinfold measurements depends on the skill of the measurer and the characteristics of the subject. Individuals differ considerably in skin thickness, together with the amount and composition of subcutaneous adipose tissue and muscle tone. It would appear from the present study that there is little to choose between BIA and SFA when estimating FFM in healthy people. Other studies report that BIA has little or no advantage over SFA, again in healthy subjects (Diaz et al. 1989; Fuller \& Elia, 1989). Lukaski et al. (1986) report an improvement in the prediction of body fat by BIA over anthropometry, but the differences are not large in healthy, normal-weight adults (a predictive error of $2.7 \%$ for BIA v. $3.9 \%$ for SFA). Both methods are non-invasive, do not require expensive equipment and take little time to perform. The $\mathrm{CV}$ for the two methods show that there is a slight advantage in using BIA (CV $1 \%$ for whole body) rather than SFA (CV 1.4\% when all measurements are made by the same operator). Previous work (reviewed by Harrison et al. 1988) shows that not only does reliability vary between skinfold sites but also inter-observer errors are greater than intraobserver errors. In addition, BIA can also be used in situations where the subject is unable to stand in order to have skinfold measurements taken.

The comparatively poor correlation between muscle mass derived from creatinine excretion and DEXA is likely to be related to differences in diet (especially meat consumption) or errors in the urine collection time, with a 15 min error in collection time causing a $1 \%$ error in the estimate of muscle mass. To overcome this problem a $3 \mathrm{~d}$ urine collection period has been suggested (Heymsfield et al. 1983). However, as several clinical studies (Heymsfield et al. 1983; Shanbhogue et al. 1987; Schneeweiss et al. 1990) have only used $24 \mathrm{~h}$ urinary creatinine collection to estimate FFM (even in patients with hepatic disease), we felt that the results of one $24 \mathrm{~h}$ collection would be comparable with those studies as well as being more practical for the volunteer subjects.

It has been suggested that BIA can be applied to study the distribution of body water between the intracellular (ICW) and extracellular (ECW) phases by the use of multiple frequencies in place of a single frequency as at present. This approach has been validated in healthy male subjects by Segal et al. (1991), but it remains to be seen whether this technique can be applied to patients in an abnormal hydration state. Studies undertaken by McCullough et al. (1991) indicate that BIA alone is inaccurate for determining total 
body water and ECW in cirrhosis, and tracer isotope-dilution techniques may be required in addition to BIA for patients with ascites. Care must be taken in the interpretation of body composition data acquired by DEXA, as this is also affected by the state of hydration of the subject. DEXA measures total body water as lean tissue and it is not possible to distinguish between ICW and ECW. The validation studies that have been reported refer only to relatively young, non-obese healthy adults (Gotfredsen et al. 1986; Hassager et al. 1989; Heymsfield et al. 1989).

The present study verifies that body composition can be estimated in healthy subjects from measurements of $Z_{\mathrm{a}}$ and $L_{\mathrm{a}}$, assuming that the composition of the arm is representative of the rest of the body. BIA of the arm offers a simple, cheap and reliable method for assessing body composition in man where whole-body measurements may not be possible. Further studies are necessary to confirm the validity of segmental impedance measurements in a clinical situation examining groups of patients with abnormal body composition or excessive fluid retention.

The authors wish to thank $\mathrm{Mr} \mathrm{K}$. Brooks for his assistance with the anthropometric measurements, and the Medical Research Council for its support of this work.

\section{REFERENCES}

Baumgartner, R. N., Chumlea, W. C. \& Roche, A. F. (1989). Estimation of body composition from bioelectrical impedance of body segments. American Journal of Clinical Nutrition 50, 221-226.

Clarys, J. P. \& Marfell-Jones, M. J. (1986). Anatomical segmentation in humans and the prediction of segmental masses from intra-segmental anthropometry. Human Biology 58, 771-782.

Diaz, E. O., Villar, J., Immink, M. \& Gonzales, T. (1989). Bioimpedance or anthropometry? European Journal of Clinical Nutrition 43, 129-137.

Durnin, J. V. G. A. \& Womersley, J. (1974). Body fat assessed from total body density and its estimation from skinfold thicknesses: measurements on 481 men and women aged 16-72 years. British Journal of Nutrition 32, $77-92$.

Fuller, N. J. \& Elia, M. (1989). Potential use of bioelectrical impedance of the 'whole body' and of body segments for the assessment of body composition: comparison with densitometry and anthropometry. European Journal of Clinical Nutrition 43, 779-791.

Gotfredsen, A., Jensen, J., Borg, J. \& Christiansen, C. (1986). Measurement of lean body mass and total body fat using dual photon absorptiometry. Metabolism 35, 88-93.

Harrison, G. G., Buskirk, E. R., Carter, J. E., Johnston, F. E., Lohmon, T. G., Pollock, M. L., Roche, A. F. \& Wilmore, J. (1988). Skinfold thicknesses and measurement technique. In Ahthropometric Standardization Reference Manual, pp. 55-80 [T. G. Lohman, A. F. Roche and R. Martorell, editors]. Champaign, Illinois: Human Kinetic Books.

Hassager, C., Sorensen, S. S., Nielsen, B. \& Christiansen, C. (1989). Body composition measurement by dual photon absorptiometry: comparison with body density and total body potassium measurements. Clinical Physiology 9, 353-360.

Heymsfield, S. B., Arteaga, C., McManus, C., Smith, J. \& Moffitt, S. (1983). Measurement of muscle mass in humans: validity of the 24-hour urinary creatinine method. American Journal of Clinical Nutrition 37, 478-494.

Heymsfield, S. B., McManus, C., Smith, J., Stevens, V. \& Nixon, D. W. (1982). Anthropometric measurement of muscle mass : revised equations for calculating bone-free arm muscle area. American Journal of Clinical Nutrition 36, $680-690$.

Heymsfield, S. B., Wang, J., Heshka, S., Kehayias, J. J. \& Pierson, R. N. (1989). Dual photon absorptiometry: comparison of bone mineral and soft tissue mass measurements in vivo with established methods. American Journal of Clinical Nutrition 49, 1283-1289.

Hoffer, E. C., Meador, C. K. \& Simpson, D. C. (1969). Correlation of whole-body impedance with total body water volume. Journal of Applied Physiology 27, 531-534.

Lukaski, H. C. (1987). Methods for the assessment of human body composition: traditional and new. American Journal of Clinical Nutrition 46, 537-556.

Lukaski, H. C., Bolonchuk, W. W., Hall, C. B. \& Siders, W. A. (1986). Validation of tetrapolar bioelectrical impedance method to assess human body composition. Journal of Applied Physiology 60, 1327-1332.

Lukaski, H. C., Johnson, P. E., Bolonchuk, W. W. \& Lykken, G. I. (1985). Assessment of fat-free mass using bioelectrical impedance measurements of the human body. American Journal of Clinical Nutrition 41, 810-817.

McCullough, A. J., Mullen, K. D. \& Kalhan, S. C. (1991). Measurements of total body and extracellular water in cirrhotic patients with and without ascites. Hepatology 14, 1102-1111. 
Mazess, R. B., Barden, H. S., Bisek, J. P. \& Hanson, J. (1990). Dual-energy X-ray absorptiometry for total-body and regional bone-mineral and soft-tissue composition. American Journal of Clinical Nutrition 51, 1106-1112.

Mazess, R. B., Peppler, W. W. \& Gibbons, M. S. (1984). Total body composition by dual-photon $\left({ }^{153} \mathrm{Gd}\right)$ absorptiometry. American Journal of Clinical Nutrition 40, 834-839.

Presta, E., Segal, K. R., Gutin, B., Harrison, G. G. \& Van Itallie, T. B. (1983). Comparison in man of total body electrical conductivity and lean body mass derived from body density: Validation of a new body composition method. Metabolism 32, 524-527.

Schneeweiss, B., Graninger, W., Ferenci, P., Eichinger, S., Grimm, G., Schneider, B., Laggner, A. N., Lenz, K. \& Kleinberger, G. (1990). Energy metabolism in liver disease. Hepatology 11, 387-393.

Segal, K. R., Burastero, S., Chun, A., Coronel, P., Pierson, R. N. \& Wang, J. (1991). Estimation of extracellular and total body water by multiple-frequency bioelectrical-impedance measurement. American.Journal of Clinical Nutrition 54, 26-29.

Settle, R. G., Foster, K. R., Epstein, B. R. \& Mullen, J, L. (1988). Nutritional assessment: whole body impedance and body fluid compartments. Nutrition and Cancer 2, 72-80.

Shanbhogue, R. L. K., Bistrian, B. R., Jenkins, R. L., Jones, C., Benotti, P. \& Blackburn, G. L. (1987). Resting energy expenditure in patients with end-stage liver disease and in normal population. Journal of Parenteral and Enteral Nutrition 11, 305-308. 